\title{
Experiência Cotidiana: a Visão da Pessoa com Estomia Intestinal
}

Everyday Experience: a Vision of the Person with Intestinal Ostomy

La Experiencia Cotidiana: la Visión de la Persona con Estoma Intestinal

\author{
Dayse Carvalho do Nascimento', Carolina Costa Chagas' ${ }^{1}$, Norma Valéria Dantas de Oliveira Souza', \\ Graciete Saraiva Marques', Fernanda Rocha Rodrigues', Clicia Vieira Cunha', \\ Deborah Machado dos Santos', Patricia Alves dos Santos Silva?
}

\begin{abstract}
RESUMO
Durante o Curso de Residência em Enfermagem, os residentes entram em contato com a mais variada diversidade de doenças e experiências, das quais destaca-se o convívio com pessoas com estomias intestinais. A estomia consiste em uma comunicação artificial dos órgãos com o meio externo, podendo ser confeccionada para drenagens, eliminações fisiológicas ou nutrição. O objetivo do estudo foi identificar as situações relatadas pelas pessoas com estomias em relação à estomia intestinal e analisar a nova experiência cotidiana vivenciada. Trata-se de uma pesquisa de campo, com abordagem qualitativa. A coleta de dados foi realizada por meio de questionário semiestruturado com dez pacientes acompanhados por um grupo de apoio, em um hospital universitário do estado do Rio de Janeiro. A análise dos dados foi realizada de acordo com a perspectiva de Bardin. Os resultados qualitativos originaram três categorias: gerenciamento do cotidiano frente ao surgimento de atividades limitantes; diversidade emocional na compreensão da nova realidade; e importância das orientações de saúde como suporte à pessoa com estomia. Conclui-se que na experiência cotidiana a pessoa com estomia se depara com um conjunto complexo de emoções e que cada indivíduo lida de maneira pessoal com os conflitos, no entanto, é possível ter uma vida normal. Evidenciou-se ainda a importância da equipe multiprofissional e o papel vital do enfermeiro no suporte e na recuperação dessa clientela.
\end{abstract}

DESCRITORES: Estomia. Atividades cotidianas. Adaptação. Cuidados de enfermagem. Estomaterapia.

\begin{abstract}
During the Residency Program in Nursing, residents come in contact with the widest variety of conditions and experiences, from which we can highlight the contact with patients with intestinal ostomy. The ostomy consists of an artificial organ communication with the external environment, which may be made for drainage, deletions or physiological nutrition. The objective of the study was to identify situations reported by patients with intestinal ostomies and to analyze the new everyday experience. This is a field research with qualitative approach. Data collection was performed using a semi-structured questionnaire with ten patients followed by a support group for ostomy in a university hospital in the State of Rio de Janeiro, Brazil. Data analysis was performed according to the Bardin's perspective. Qualitative results yielded three categories: daily management of ostomy patients due to the emergence of limiting activities; emotional diversity in understanding the new reality; and importance of health guidelines in support for patients with ostomy. It was concluded that ostomates face a complex set of emotions and that each individual deals in a personal way with the conflict, however, it is possible to have a normal life. It also highlighted the importance of the multidisciplinary team and the vital role of nurses in support and recovery of this clientele.
\end{abstract}

DESCRIPTORS: Ostomy. Activities of daily living. Adaptation. Nursing care. Stomatherapy.

${ }^{1}$ Universidade do Estado do Rio de Janeiro (UERJ) - Rio de Janeiro (RJ), Brasil. Endereço para correspondência: Dayse Carvalho Do Nascimento Boulevard 28 de setembro, 77, $3^{\circ}$ andar - Vila Isabel - CEP: 20551030 - Rio de Janeiro (RJ), Brasil - Email: daysecnascimento@hotmail.com Artigo recebido em: 01/04/2016 - Aceito para publicação em: 24/05/2016 


\section{RESUMEN}

Durante el Programa de Residencia en Enfermería, los residentes entran en contacto con la más amplia variedad de condiciones y experiencias, de las cuales podemos destacar convivir con personas con estomas intestinales. La estomía consiste en una comunicación artificial de los órganos con el ambiente externo, que puede estar hecho para el drenaje, supresiones o la nutrición fisiológica. El objetivo del estudio fue identificar las situaciones reportadas por las personas con estomía sobre la estomía intestinal y analizar la nueva experiencia cotidiana vivida. Se trata de una investigación de campo con enfoque cualitativo. La recolección de datos se realizó mediante un cuestionario semiestructurado con diez pacientes seguidos por un grupo de apoyo para estomía en el hospital de la Universidad del Estado de Río de Janeiro, en Brasil. El análisis de datos se realizó de acuerdo a la perspectiva de Bardin. Los resultados cualitativos produjeron tres categorías: la gestión del cotidiano debido a la aparición de las actividades limitantes; la diversidad emocional en la comprensión de la nueva realidad; y la importancia de las directrices de salud en el apoyo a la persona con estomía. De ello se desprende que los ostomizados se enfrentan a un complejo conjunto de emociones y que cada individuo enfrenta de manera personal el conflicto, sin embargo, es posible que los pacientes de estomía tengan una vida normal. También puso de relieve la importancia del equipo multiprofesional y el papel vital de las enfermeras en el apoyo y en la recuperación de esta clientela.

DESCRIPTORES: Estomía. Actividades cotidianas. Adaptación. Atención de enfermería. Estomoterapia.

\section{INTRODUÇÃO}

A rotina de trabalho e o cotidiano dentro das enfermarias possibilita ao residente de enfermagem uma enriquecedora troca de experiências com os pacientes, ajudando a fortalecer a relação entre o cuidador e o cuidado, transformando essa relação em um vínculo de confiança, na qual o paciente encontra uma fonte de apoio no profissional, permitindo que suas ações sejam direcionadas a uma assistência mais específica e integral.

Uma das situações que merece destaque durante esse convívio é a admissão e o contato direto com pacientes estomizados ou com previsão de confeccionarem uma estomia intestinal. A convivência com essa clientela traz à tona o universo em que a pessoa com estomia está inserida e desperta $\mathrm{o}$ interesse em aprofundar conhecimentos sobre a vivência e as concepções do indivíduo frente à estomia intestinal, uma vez que essa mudança gera transformações significativas em diversos aspectos da vida, desde os aspectos biológicos até sociais e psicológicos, consequentemente, trazendo grandes desafios a esse paciente.

O conceito de estomia surge como uma palavra derivada do grego e que significa a abertura de uma boca ou comunicação entre um órgão interno e o exterior, com o intuito de completar a função do órgão que está afetado, assim, essas podem ser confeccionadas para drenagens, eliminações fisiológicas e ainda para a nutrição, sendo o objeto de estudo deste trabalho as estomias de eliminação, especificamente a estomia intestinal ${ }^{1,2}$.
Atualmente, a sociedade moderna convive com a realidade do aumento da expectativa de vida, proporcionada pela urbanização crescente e a constante industrialização mundial. No entanto, paralelamente, observa-se um maior adoecimento da população somado a hábitos de vida cada vez mais inadequados, o que acarreta aumento de comorbidades e incidência de doenças crônicas, como o câncer ${ }^{3,4}$.

A tecnologia cada vez mais avançada, principalmente na área de saúde, contribui para o diagnóstico precoce de doenças e a intervenção mais adequada e necessária traduz-se na forma de intervenções cirúrgicas que proporcionam uma melhor qualidade de vida para a pessoa, como as cirurgias de confecção de estomias ${ }^{3}$. Apesar da pouca produção científica acerca da epidemiologia das estomias, a Associação Brasileira de Ostomizados (ABRASO) estima que o quantitativo de estomizados no Brasil seja, aproximadamente, de 33.844 pessoas $^{5}$. Porém, esse dado pode não representar o número real de estomizados devido à subnotificação.

Sabe-se que o cuidado e a assistência, na sua forma mais tecnicista, são as prioridades do profissional de enfermagem, e que esse pode não estar preparado para uma escuta humanizada, que possibilite ao paciente expor suas dúvidas e receios, o que acaba privando esse indivíduo de um cuidado mais focal e individualizado.

A partir disso, cabe ao profissional de enfermagem um olhar diferenciado e uma assistência acolhedora para questões complexas que certamente surgem para esse paciente, até mesmo para que possa desenvolver um plano de cuidado específico e contínuo. $\mathrm{O}$ estomizado exige uma assistência 
de enfermagem que contribua para sua reabilitação para além das barreiras institucionais, e para que isso aconteça, é necessário conhecer as problemáticas emergentes desses indivíduos ${ }^{1,6}$.

Nesse contexto, o presente estudo justifica-se pela necessidade de ampliar e aprofundar o conhecimento sobre a clientela com estomia, visto que constitui parte dos atendimentos ambulatoriais e das internações hospitalares, evidenciando que o profissional de enfermagem está em contato direto com essas pessoas em todos os níveis de assistência à saúde.

E para atender ao estudo, os objetivos foram: identificar as situações relatadas pelos estomizados participantes do estudo em relação à estomia intestinal e analisar a nova experiência cotidiana vivenciada.

\section{MÉTODOS}

Trata-se de uma pesquisa de campo, com abordagem qualitativa, de caráter exploratório. Esse tipo metodológico de pesquisa foi selecionado por abordar estudos das ciências sociais, pois se entende que a questão "saúde e doença" agrega questões socioculturais de grande relevância e que, muitas vezes, não podem ser traduzidas somente em uma abordagem numérica e estatística ${ }^{7}$. E, ainda, por trabalhar com simbolismos e significados, auxiliando na compreensão do processo saúde-doença, promovendo o estreitamento de relações entre profissionais, pacientes e familiares, permitindo um maior entendimento de questões emocionais e comportamentais, tanto dos pacientes como da própria equipe de saúde ${ }^{8}$.

O cenário do estudo envolveu um grupo multidisciplinar de apoio a pessoas estomizadas, localizado no setor de clínica cirúrgica de um hospital universitário do estado do Rio de Janeiro. Os participantes foram dez pacientes estomizados, convidados a participar, internados ou pós alta, e a seguir acompanhados por esse grupo. A coleta de dados foi realizada por meio de questionário semiestruturado (pré-testado para assegurar validade e aplicabilidade durante a pesquisa) durante três meses (agosto a outubro de 2014). Cada participante foi identificado com uma letra do alfabeto para uma melhor análise dos dados posteriormente. O projeto foi aprovado pelo Comitê de Ética em Pesquisa (CEP: 721286, em 09 de julho de 2014) e foram respeitados os preceitos éticos da Resolução no 466/12, do Conselho Nacional de Saúde, observando-se a livre aceitação dos sujeitos em participar do estudo e a assinatura do Termo de Consentimento Livre e Esclarecido.

A análise dos dados coletados foi realizada na perspectiva de Bardin, conhecida como análise de conteúdo, o que permitiu a reprodução e validação de inferências sobre os dados, utilizando procedimentos especializados e específicos, com temas codificados e categorizados ${ }^{7,9}$.

\section{RESULTADOS E DISCUSSÃO}

\section{Perfil dos participantes do estudo}

A caracterização dos participantes foi realizada com base em dados sociodemográficos, dados referentes aos fatores desencadeantes e tempo de estomia, conforme mencionado nas Tabelas 1 e 2.

Embora atualmente existam vários estudos que abordem questões relacionadas aos estomizados, ainda são escassos os estudos epidemiológicos que retratem o perfil dessa clientela. Sabe-se, no entanto, que grande parte dos estomas intestinais surge em consequência de intervenções cirúrgicas e não constituem causas ou diagnósticos ${ }^{10}$.

\section{Categorias analíticas}

O corpus do estudo foi composto por 10 questionários, originando 59 unidades de registro agrupadas em 3 categorias, sendo essas o resultado final da codificação e categorização do material discursivo analisado. Os resultados revelaram questões sobre as limitações físicas e sociais, diminuição da sociabilidade, insegurança com a família, dificuldade com a autoimagem, o papel da espiritualidade e a importância dos profissionais de saúde.

Observa-se, no Quadro 1, a organização categórica final resultante da análise dos dados, bem como a visualização da proporção numérica das unidades de registro encontradas em cada categoria do presente estudo, de acordo com a tendência das respostas seguidas pelos sujeitos da pesquisa.

\section{Gerenciamento do cotidiano do estomizado frente ao surgimento de atividades limitantes}

Nessa categoria os pacientes estomizados indicam os fatores limitadores das atividades diárias em decorrência da presença da estomia, sejam esses fatores de caráter físico-biológico ou sociocultural, que irão impactar de alguma forma na adaptação da vida pós-estomia desses sujeitos. 
Tabela 1. Caracterização dos participantes com base em dados sociodemográficos. Rio de Janeiro (RJ), 2014.

\section{Característica}

n (\%)

Idade (anos)

$\begin{array}{cc}21 \text { a } 51 & 1(10) \\ 52 \text { a } 62 & 4(40) \\ 63 \text { a } 83 & 5(50)\end{array}$

Sexo

Feminino

Masculino

Raça

\begin{tabular}{lc} 
Brancos & $6(60)$ \\
\hline Pardos & $3(30)$ \\
\hline Negros & $1(10)$
\end{tabular}

Estado civil

\begin{tabular}{lc} 
Casado & $7(70$ \\
Solteiro & $2(20)$ \\
\hline Viúvo & $1(10)$
\end{tabular}

Ocupação

Do lar

Comerciante

Motorista

Aposentado

Estudante

Não responderam

Escolaridade

Ensino Fundamental

Ensino Médio

Ensino Superior

Religião

\begin{tabular}{lc} 
Católica & $4(40)$ \\
\hline Evangélica & $4(40)$ \\
\hline Não responderam & $2(20)$
\end{tabular}

Filhos

$\begin{array}{ll}\mathrm{Sim} & 7(70) \\ \text { Não } & 3(30)\end{array}$

Renda familiar (salários mínimos)

1 a $3 \quad 10(100)$
Essa categoria agrupa os discursos dos sujeitos em relação às barreiras de cunho físico, encontradas a partir do momento em que a estomia, muitas vezes, possibilita um manejo dificultoso de atividades consideradas simples antes de se tornar um portador de estomia intestinal. Em decorrência dessas dificuldades, o estilo de vida da pessoa estomizada é afetado, passando a conviver com uma capacidade limitada para diversas atividades, fazendo com que esse indivíduo busque, constantemente, adequação e ajuste da sua nova realidade.

A vivência conflituosa no campo das adaptações físicas é abordada no relato do incômodo dos pacientes estomizados associado ao uso de dispositivos, como a bolsa coletora, pois além do surgimento do sentimento de perda de autonomia corporal, esses dispositivos impõem algumas restrições em

Tabela 2. Caracterização dos participantes com base nos fatores desencadeantes e tempo de estomia. Rio de Janeiro (RJ), 2014.

\begin{tabular}{lc}
\hline Característica & n (\%) \\
\hline Causas básicas & $2(20)$ \\
Doença de Crohn & $2(20)$ \\
Câncer de cólon & $3(30$ \\
Fístula intestinal & $1(10)$ \\
Apêndice supurado & $1(10)$ \\
Acidente por arma de fogo & $1(10)$ \\
Não responderam & $4(40)$ \\
Tempo de estomia & $6(60)$ \\
\hline Menos de 1 ano
\end{tabular}

Quadro 1. Categorias analíticas e unidades de registro.

\begin{tabular}{|ll|}
\hline Categorias & $\begin{array}{c}\text { Unidades } \\
\text { de registro }\end{array}$ \\
\hline
\end{tabular}

1. Gerenciamento do cotidiano do estomizado frente ao surgimento de atividades limitantes

2. A diversidade emocional na compreensão da nova realidade 16 3. A importância das orientações de saúde no suporte ao paciente estomizado

Total 26 17 59 
atividades rotineiras que antes eram executadas de forma natural e, até então, desvalorizadas ${ }^{11}$.

Fazer qualquer tipo de esforço. (A)

Pegar pesos. (C)

Fazer faxina. (D)

Não pode pegar peso. (D)

Dificulta pegar peso. (E)

Atividades com arrumação da casa. (F)

Ao analisar a descrição dos sujeitos do estudo acerca das principais dificuldades físicas encontradas, é possível reconhecer o predomínio de afirmações voltadas para a impossibilidade de se pegar peso ou a recomendação de se evitar pegar peso. $\mathrm{O}$ ato de fazer esforço físico é relevante e orientado a todos os pacientes estomizados, pois as principais complicações que podem surgir após a construção da estomia são hérnia, prolapso de alça intestinal e deiscência de suturas que são evitáveis quando o paciente recebe orientação adequada ${ }^{11}$.

Diante desses fatos, pode-se afirmar que esse indivíduo necessitará não apenas de um ajuste que envolva somente a adequação aos novos dispositivos e rearranjo de suas atividades comuns, mas deverá desenvolver o entendimento de que certas ações fazem parte das noções de autocuidado e prevenção de agravos, possibilitando a manutenção da saúde e de uma estomia sempre sadia e livre de complicações.

A adaptação do estomizado em relação às restrições físicas ocorre com o passar do tempo e depende da maneira como acontece a evolução da doença. Dessa forma, o indivíduo vai naturalmente desenvolvendo estratégias de enfrentamento das complicações que ocorrem no seu cotidiano devido à presença da estomia, não havendo previsão para sua completa adaptação, que pode ocorrer entre alguns dias ou meses ${ }^{12}$.

Além das restrições físicas, os discursos evidenciam também restrições de atividades no âmbito social, originadas pela presença da estomia intestinal, e que por sua vez, se transformam em verdadeiros dilemas, alterando a configuração da rede social daquele indivíduo.

O fato de iniciar uma nova trajetória de vida como pessoa estomizada faz surgir uma série de dúvidas, dentre elas, a possibilidade de manutenção ou não das suas atividades sociais e de lazer dentro da normalidade ${ }^{13}$. A falta de segurança e confiabilidade nos dispositivos coletores é uma das principais razões que levam os sujeitos da pesquisa ao bloqueio de determinadas atividades sociais. Certamente, cada indivíduo possui um tipo de enfrentamento diferente, visto que cada um se comporta de forma peculiar e individual frente aos conflitos socioculturais. No entanto, o predomínio do medo e da insegurança conduz à supressão da atividade abordada.

\section{A ostomia impede de frequentar piscina, fui uma vez (...) e a bolsa descolou. (C) \\ Medo de sair na rua porque achava que a bolsa ia vazar. (D)}

Mesmo diante do esforço de alguns em retomar as atividades de lazer, encontramos a insegurança relacionada ao uso do dispositivo por motivos mecânicos, como a aderência $\mathrm{da}$ bolsa à parede abdominal e a possibilidade de vazamento da mesma ${ }^{14}$ impedem que a pessoa possa desfrutar adequadamente desses momentos de lazer. Isso também se relaciona com o afastamento de atividades laborais e, não raro, de se encontrar com outros indivíduos, já que a insegurança pode se fazer presente ao retornar ao ambiente de trabalho.

Além disso, a condição de estomizado implica em algumas limitações físicas, ditas anteriormente neste estudo, que podem influenciar na capacidade produtiva e dificultar o retorno ao trabalho, abrindo a possibilidade para a construção de um arcabouço de sentimentos ligados à inutilidade, que muitas vezes resulta em aposentadoria precoce e recebimento de auxílio-doença ${ }^{15-17}$.

\section{A diversidade emocional na compreensáo da nova realidade}

Foram reunidos nessa categoria os sentimentos e as emoções expressadas pelos sujeitos, relacionados às dúvidas e ao medo das possíveis reações dos indivíduos de seu círculo social e familiar, além de suas próprias reações, mediante a presença do estoma.

Essa categoria abarca os discursos que se destacam pela alteração de comportamento social, muitas vezes caracterizado pelo isolamento diante de sentimentos conflituosos acerca da nova configuração corporal. É a alteração física do indivíduo que engloba toda a origem do confronto de emoções, que se refletem na forma como essa pessoa irá se comportar no mundo externo.

Ao defrontar-se com o discurso apresentado pelos sujeitos, foi possível constatar que a vergonha pela sua nova condição era fator determinante para a reconfiguração do seu panorama social. Sem a certeza de como a sociedade poderá reagir à presença de um orifício no seu abdome, muitos preferem adotar a conduta de isolamento, antevendo situações 
de constrangimento e julgamentos de amigos e pessoas próximas. Esse padrão de comportamento é abordado na literatura, na qual se discute o deslocamento sentido pelo estomizado por não se enquadrar na sociedade considerada normal e começa a experimentar uma supressão do convívio social que os faz imergir quase sempre em uma desordem emocional alternada entre angústia e solidão ${ }^{16}$.

Evito encontrar amigos, vergonha dos amigos. (B)

Ficava só em casa. (B)

Vergonha e discriminação pelo jeito que as pessoas

me tratavam. $(\mathrm{H})$

O estomizado entende, muitas vezes, que para não sofrer com o medo de ser julgado, a solução é não tornar pública a sua estomia e, dessa forma, vai se envolvendo cada vez mais em uma situação de declínio social ${ }^{6}$. Além disso, o fato de terem a ordem fisiológica do trato gastrointestinal alterada gera receios como à percepção dos odores provenientes dos gases e a visualização da eliminação fecal por pessoas ao redor, constituindo mais um elemento propulsor para a vergonha, o que compromete cada vez mais o contato dessa pessoa com os membros da comunidade ${ }^{18}$.

A família representa a possibilidade de desenvolver-se como elemento apoiador nessa nova realidade, destacando-se como agente atuante na recuperação do mesmo, e ainda, caracterizando-se como um fator tão importante quanto o âmbito social na oportunidade de reabilitação positiva da pessoa estomizada.

No entanto, ao mesmo tempo em que constitui um poderoso elemento facilitador da reabilitação, a família pode não se encontrar preparada para algo que também é novo e desconhecido para ela, que também necessitará de tempo para a adaptação. A presença das crenças e valores de cada instituição familiar no processo de adaptação pode ser natural ou mais espinhoso, ou seja, cada família irá desenvolver uma maneira própria de encarar esse processo, sendo necessárias paciência e compreensão mútua entre os membros durante essa fase ${ }^{18,19}$.

A preocupação em relação às reações da família para com a representatividade da estomia se fez presente nas respostas apresentadas pelos sujeitos, transparecida principalmente pela insegurança e baixa autoestima frente aos filhos e pelo medo da possibilidade de rejeição do parceiro.

Visto que a realização de uma estomia representa uma mudança drástica na composição corporal do indivíduo, torna-se notória a constatação de que essas pessoas dificilmente encontram-se preparadas para lidar com o conflito de sua nova autoimagem, ocasionando estados frequentes de angústia e baixa autoestima. Esses sentimentos negativos que dizem respeito à imagem do próprio corpo se inserem no contexto familiar, comprometendo, por diversas vezes, os relacionamentos entre os membros ${ }^{17-19}$. Então, é reforçada a intervenção familiar como elemento de alicerce ao cuidado, não como cuidado técnico, e sim como um cuidado emocional que possa estabelecer confiança e acolhimento, onde possa existir voz ao estomizado para expressar sentimentos frequentes de medos e tristezas ${ }^{18}$. Dessa forma, nasce a possibilidade de reerguer sua autoestima graças à colaboração em família para o enfrentamento dessa nova situação. E para tanto, obter o auxílio da família e do parceiro é essencial nesse cenário de mudanças, pois uma vez constatada a ausência de apoio da família, torna-se iminente a chance do estomizado adotar comportamentos de isolamento social e até mesmo configurar o afastamento da expressão da sexualidade ${ }^{19,20}$.

Fiquei com medo e vergonha pelo meu marido não aceitar.(D) Vergonha pela família. (I)

A sexualidade quase sempre vem acompanhada de muito tabu para o estomizado, pois a angústia com o comportamento e a aceitação do parceiro passa a compor um impasse interno e que muitas vezes não é expresso pelo indivíduo, estando diretamente relacionado a questões anatômicas e fisiológicas, mas também claramente conectado a questões psicológicas que refletem tradições, crenças e o contexto sociocultural em que essa pessoa está inserida ${ }^{20}$. Faz-se necessário dialogar e compartilhar com o parceiro o processo saúde-doença desde o princípio, permitindo que o mesmo se envolva nessa nova fase e possibilitando, dessa forma, que o estomizado tenha liberdade e conforto para expressar seus sentimentos, resultando no recebimento de apoio emocional, que irá refletir mais à frente no sucesso da reabilitação e da adaptação à estomia ${ }^{20}$.

Diante disso, pode-se afirmar que a família se configura como eixo norteador em direção à recuperação da pessoa estomizada e sua atuação principal é nos primeiros momentos após a confecção da estomia, justamente quando a pessoa está lidando com sentimentos que nem ela mesma compreende, além da necessidade de reaprender a gerenciar o seu autocuidado. Os familiares integram um papel 
essencial no suporte emocional, criando laços de força e união que impulsionam esse indivíduo a uma melhor qualidade de vida ${ }^{11,16}$.

Os aspectos predominantemente apontados pelos participantes foram o surgimento do medo e a da insegurança ao lidar com uma realidade totalmente desconhecida para eles, e que foi imposta de maneira repentina. Muitos informaram que vivenciaram uma gama de sentimentos desordenados devido à complexidade de uma situação que eles não estavam preparados para viver. A formação foi elaborada a partir dos discursos que exprimiam o conjunto de opiniões dos estomizados acerca de si próprios, revelando a compreensão da sua nova condição e assimilação da nova imagem corporal, devido à necessidade súbita de lidar com um rearranjo profundo em suas vidas.

Diversas pessoas não possuem o conhecimento do significado do que é uma estomia, até o momento em que se deparam com uma doença e com a necessidade do procedimento cirúrgico. Logo, é natural a surpresa e o surgimento de angústias, dúvidas e questionamentos acerca de como será o cenário de sua vida a partir de então. Esses sentimentos gerados pela presença de um estoma acarretam na obrigatoriedade de saber conviver em harmonia com o ambiente e com si próprio ${ }^{15,16,21}$. Sendo assim, uma das tarefas mais difíceis é a tentativa de harmonização do sentimento para com o próprio corpo. Nota-se, através da linguagem apresentada pelos sujeitos da pesquisa, que a estomia compreende não somente uma violação de caráter fisiológico, mas também influencia na ruptura e no declínio da autoimagem. Foi explicitado em alguns discursos a sensação de invalidez causada pela presença da estomia intestinal e a angústia de ter que conviver com um elemento estranho que agora está vinculado ao seu corpo, causando sofrimento e consequente alteração da autoestima.

Me sinto como uma inválida, não consigo levar uma vida normal. (A)

Medo, angústia e insegurança porque foi muito difícil pra mim. (C)

Era tudo muito novo, por isso fiquei insegura. (D)

Isso é um tipo de doença que acaba com a autoestima de qualquer pessoa. ( $\mathrm{J}$ )

Isto é explicitado na literatura, que a partir do momento em que a pessoa se vê portadora de uma estomia intestinal, é esperado que esse indivíduo comece a sustentar uma fase de negação, composta de diversas sensações em relação ao seu corpo, como a rejeição de si próprio e a sensação de retalhamento e mutilação. Ademais, a literatura traz também que a estomia pode carrear uma forte característica estigmatizante, responsável por originar a não aceitação e a criar perturbações emocionais em função do reflexo de sua imagem atual, podendo afetar o convívio na sociedade, como já foi dito anteriormente neste estudo ${ }^{15,18,19,21}$.

O conceito de estética corporal possui elementos subjetivos e pessoais, independentemente de como a pessoa enxerga a si mesma. Logo, ao adquirir uma estomia intestinal, a imagem que o paciente tinha elaborado sobre seu corpo pode ser destruída automaticamente, na maioria dos casos. A estomia traz configurações anatômicas completamente diferentes do usual, como o uso da bolsa coletora, necessidade de adaptar o vestuário, entre outras alterações. Logo, deve-se respeitar o período de adequação desse indivíduo ${ }^{11,19}$.

De acordo com os discursos encontrados, está explícito que muitos encontram na religião, na crença e na fé uma forma de conforto, apoio, e de certa forma até resignação com sua atual condição. Alguns chegaram a manifestar o desejo de serem curados pela fé. Observa-se que também existe aquele que não cita especificamente uma crença, mas desempenha um papel otimista e positivo nessa nova fase de sua vida, conseguindo reconhecer que o fator "tempo" foi imprescindível para amadurecer a ideia de aceitação da estomia intestinal. A abordagem aqui diz respeito aos discursos relacionados à manutenção da crença religiosa e da esperança como facilitadores no enfrentamento do processo saúde-doença, evidenciando que alguns indivíduos conseguem avistar um caminho positivo mesmo diante do diagnóstico da doença e da constatação da necessidade da estomia.

\section{Sou uma pessoa de muita fé. (F)}

Esperança em Deus na minha melhora. $(\mathrm{H})$

É possível constatar que a procura por um auxílio superior, que transcenda o plano terreno, sempre acrescenta um caráter de apoio e esperança, dando a força necessária para que aquele indivíduo possa enfrentar os desafios impostos no seu dia a dia pela estomia. A busca pela fé, tanto quanto o refúgio na religião, podem até proporcionar que o indivíduo se sinta seguro e confiante no tratamento de sua doença, logo, é inegável o benefício 
da espiritualidade, pois através dela é possível o conforto e a esperança de dias melhores ${ }^{16,17}$.

O ser humano compreende muitas vezes a fé como um verdadeiro alívio para sua dor e entende que a ajuda divina vem para somar na batalha de dificuldades do cotidiano. A aproximação com Deus resulta em um apoio invisível, porém poderoso, que permite ao estomizado encarar sua realidade de forma mais branda. O sofrimento advindo passa a ser suportável, e até mesmo esquecido quando em contato com o divino, permitindo que essa pessoa desenvolva um olhar de esperança e se lance em busca de melhorar suas condições de vida ${ }^{19,22,23}$.

Ressalta-se, porém, que existem aqueles que não buscam na religião uma forma de suporte, mas adotam o pensamento positivo como uma estratégia de enfrentamento. Algumas pessoas com estomias desenvolvem a positividade para se defenderem de sentimentos e inquietações, conseguindo, dessa forma, um autocontrole sobre as emoções, que irá permitir com o tempo a aceitação e adaptação da situação ${ }^{24}$.

\section{A importância das orientaçóes de saúde no suporte à pessoa estomizada}

Essa última categoria foi elaborada a partir da ordenação dos discursos acerca das orientações, instruções e esclarecimentos provenientes de profissionais de saúde para com a pessoa estomizada durante o pré e o pós-operatório. Os sujeitos da pesquisa assinalaram a importância das orientações e a diferença positiva que elas desempenharam na qualidade de vida dos mesmos. A equipe de enfermagem desempenhou um papel central no pré e pós-operatório dos sujeitos, sendo que o aporte de orientações abarcou elementos técnicos, como o desenvolvimento das técnicas de autocuidado, e também elementos subjetivos, como a escuta sensível das aflições e receios dos pacientes além das tentativas de contribuir com a reinserção social dessas pessoas.

Assistente social, enfermagem. (B)

Ajuda para limpar a ileostomia. (B)

Equipe de enfermagem [...] me orientou muito bem. (C)

Dicas de sites onde eu poderia ter informações de roupas, lingerie, etc. (C)

Enfermeiros e psicólogos. (C)

Aprendi como cuidar da bolsa. (D)

Toda equipe de enfermagem e meu médico. (G)

Tive o maior apoio moral e medicinal, isso não posso reclamar.(J)
A equipe de enfermagem não deve se ater apenas a detalhes mecânicos e biológicos, como a manipulação e o cuidado com o dispositivo coletor, mas conceber também a importância em se tornar uma incentivadora e facilitadora do processo de aceitação e adaptação da estomia, bem como o fortalecimento dos laços familiares e reintegração desse sujeito na sociedade, fazendo dessas atitudes uma extensão da assistência prestada para além dos muros dos hospitais.

É importante salientar que o trabalho em equipe jamais deverá ser ignorado, pois a cada profissional de saúde cabe uma orientação diferente e única, que irá implicar em aspectos distintos na reabilitação do estomizado. A complexidade que envolve essa clientela necessita de um arcabouço de orientações, oriundas de diversos profissionais, pautando suas ações em conjunto e visando à construção de um planejamento assistencial que possibilite uma recuperação de qualidade com a consequente elevação da qualidade de vida ${ }^{6,11,21-25}$.

O espaço para a comunicação entre o paciente e o profissional deve ser construído no pré-operatório, permitindo o esclarecimento de todas as dúvidas emergentes já desde o princípio, propiciando, então, que o processo saúde-doença se estabeleça de forma mais amena e menos agressiva, cooperando com o entendimento de sua nova condição. É diante desse fato que se faz necessária a implementação de educação em saúde pelos profissionais, fornecendo informações prévias, trazendo segurança e impulsionando o estomizado para a sua autonomia ${ }^{16-18}$.

O enfermeiro qualificado deve atuar com abrangência em diversos aspectos que fragilizam a pessoa estomizada, constituindo peça-chave no desdobramento da reabilitação desses pacientes. Sendo assim, um plano de cuidados corretamente elaborado ultrapassa as questões biológicas e contempla iniciativas de reestruturação da vida social e familiar, assim como o encorajamento do retorno às suas atividades cotidianas e consequente emancipação do estomizado.

A qualificação profissional e o preparo diante da complexidade inerente a essa clientela se fazem essenciais para a prestação de uma assistência adequada. Deve-se lembrar que o profissional de saúde é elemento responsável por parte da reabilitação desses pacientes, e como tal, precisa conscientizar-se da necessidade de aprimorar e atualizar suas habilidades técnicas e de humanização.

\section{CONCLUSÃO}

Este estudo possibilitou a identificação da rotina da pessoa com estomia intestinal e do desdobramento frente às 
dificuldades surgidas diante da experiência cotidiana pela presença dessa. Os desafios perpassados pela clientela em relação ao convívio com a estomia intestinal foram evidenciados diante de um complexo conjunto de questionamentos e emoções a serem desbravados. Foi realçado, também, que cada indivíduo duela com esses conflitos de forma única e pessoal, refletindo de maneira positiva ou negativa em sua recuperação.

Nesse contexto, concluiu-se que mesmo sendo uma pessoa estomizada é possível restabelecer sua vida dentro da normalidade, pois mesmo diante de algumas restrições inerentes a essa nova condição, uma boa qualidade de vida é realizável. No entanto, para que isso seja possível, a família e o profissional de saúde precisam assumir o compromisso de compor a rede de apoio desse indivíduo, para que se estabeleça o processo de reabilitação da melhor forma possível. Logo, a importância da equipe multiprofissional é inquestionável na atuação ao paciente estomizado, já que essa é uma clientela complexa, que necessita de suporte em diversas áreas profissionais. $\mathrm{O}$ atendimento de forma multiprofissional consegue abordar o paciente como um todo, promovendo uma assistência holística que atenderá às diversas necessidades existentes diante dessa nova fase de vida e que deverá se expandir para além do atendimento hospitalar.

Destaque para a relevância da equipe de enfermagem, que desempenha um papel essencial com a pessoa estomizada, pois está presente em todas as fases que dizem respeito à construção da estomia. Concluiu-se que o profissional enfermeiro necessita manter um diálogo precoce com essa clientela, estabelecendo um binômio paciente-profissional no qual possam ser desenvolvidos a confiança e o apoio para minimizar dúvidas e sofrimentos que podem ser gerados com essa transformação.

Sendo assim, pode-se dizer que este estudo atingiu seus objetivos de forma plena, lançando um olhar criterioso para cada questão mencionada pelos sujeitos, permitindo a identificação dos principais problemas e possibilitando posteriormente a análise e a tradução detalhada da experiência cotidiana de ser estomizado, evidenciando barreiras, conflitos, dúvidas, inquietações, mas também revelando muita força de vontade, perseverança e compromisso com a vida.

\section{REFERÊNCIAS}

1. Luz MHBA, Andrade DS, Amaral HO, Bezerra SMG, Benício CDAV, Leal ACA. Caracterização dos pacientes submetidos a estomas intestinais em um hospital público em Terezina-PI. Texto Contexto Enferm, 2009;18(1):140-6.

2. Sampaio FAA, Aquino PS, Araújo TL, Galvão MTG. Assistência de enfermagem a paciente com colostomia: aplicação da teoria de Orem. Acta Paul Enferm. 2008;21(1):94-100.

3. Tosato SR, Zimmermann $\mathrm{MH}$. Conhecimento do indivíduo ostomizado em relação ao autocuidado. Revista Conexão UEPG. 2007;1(1):34-7.

4. Cunha RR, Ferreira AB, Backes VMS. Características sóciodemográficas e clínicas de pessoas estomizadas: revisão de literatura. Rev Estima. 2013;11(2):29-35.

5. Associação Brasileira de Ostomizados (ABRASO). Quantitativo aproximado de pessoas ostomizadas no Brasil. Rio de Janeiro: ABRASO; 2008. Disponível em <http://www.abraso.org.br/ estatistica_ostomizados.htm>. Acesso em 18 mar 2016.

6. Nascimento CMS, Trindade GLB, Luz MHBA, Santiago RF. Vivência do paciente estomizado: uma contribuição para a assistência de enfermagem. Texto Contexto Enferm. 2011;20(3):557-64.

7. Minayo MCS. O desafio do conhecimento: pesquisa qualitativa em saúde. 13. ed. São Paulo: Hucitec; 2013.

8. Turato ER. Métodos qualitativos e quantitativos na área da saúde: definições, diferenças e seus objetos de pesquisa. Rev Saúde Pública. 2005;39(3):507-14.
9. Bardin L. Análise de conteúdo. Lisboa: Edições 70; 2011. 281 p.

10. Moraes JT, Amaral CFS, Borges EL, Ribeiro MS. A atenção à saúde do estomizado no Estado de Minas Gerais, Brasil. Rev Estima. 2013;11(3):12-20.

11. Farias DHR, Gomes GC, Zappas S. Convivendo com uma estomia: conhecendo para melhor cuidar. Cogitare Enferm. 2004;9(1):25-32.

12. Galdino YLS, Castro ME, Pereira MLD, Lima SSO, Silva FAAS, Guedes MVC. O cotidiano da pessoa ostomizada frente às necessidades humanas básicas alteradas. Rev Estima. 2012;10(3):22-30.

13. Barnabe NC, Dell'Acqua MCQ. Estratégias de enfrentamento (coping) de pessoas ostomizadas. Rev Latino-Am Enfermagem. 2008;16(4):712-9.

14. Cassero PAS, Aguiar JE. Percepções emocionais influenciadas por uma ostomia. Revista Saúde e Pesquisa. 2009:2(2):23-7.

15. Poletto D, Silva DMGV. Viver com estoma intestinal: a construção da autonomia para o cuidado. Rev Latino-Am Enfermagem. 2013;21(2):531-8.

16. Silva AL, Shimizu HE. A relevância da rede de apoio ao estomizado. Rev Bras Enferm. 2007;60(3):307-11.

17. Silva AL, Shimizu HE. O significado da mudança no modo de vida da pessoa com estomia intestinal definitiva. Rev LatinoAm Enfermagem. 2006;14(4):483-90. 
18. Souza PCM, Costa VRM, Maruyama SAT, Costa ALRC, Rodrigues AEC, Navarro JP. As repercussões de viver com uma colostomia temporária nos corpos: individual, social e político. Rev Eletr Enf. 2011;13(1):50-9.

19. Santana JCB, Dutra BS, Tameirão MA, Silva PF, Moura IC, Campos ACV. O significado de ser colostomizado e participar de um programa de atendimento ao ostomizado. Cogitare Enferm. 2010;15(4):631-8.

20. Paula MAB, Takahashi RF, Paula PR. Os significados da sexualidade para a pessoa com estoma intestinal definitivo. Rev Bras Colo-proctol. 2009;29(1):77-82.

21. Almeida RLM, Meirelles VC, Salimena AMO, Melo MCSC. Compreendendo os sentimentos da pessoa com colostomia. Rev Estima. 2006;4(3):26-34.
22. Batista MRFF, Rocha FCV, Silva DMG, Silva Júnior FJG. Autoimagem de clientes com colostomia em relação à bolsa coletora. Rev Bras Enferm. 2011;64(6):1043-7.

23. Sales CA, Violin MR, Waidman MAP, Marcon SS, Silva MAP. Sentimentos de pessoas ostomizadas: compreensão existencial. Rev Esc Enferm USP. 2010;44(1):221-7.

24. Couto PG, Medeiros SS. Sentimentos da pessoa submetida a ostomia intestinal: uma visão holística de enfermagem. Rev Clin Hosp Prof Dr Fernando Fonseca. 2013;2(1):23-7.

25. Cascais AFMV, Martini JG, Almeida PJS. O impacto da ostomia no processo de viver humano. Texto Contexto Enferm. 2007;16(1):163-7. 